\title{
Sustainable Development Theory: A Critical Perspective and an Integrative Model
}

\begin{abstract}
Professor Shamsalsadat Zahedi PHD. Department of Management. Allameh Tabataba'i University. Tehran, Iran. Tel: 00982188099997 Abstract

The first significant effort to present "sustainable development" in a global level, has been Brundtland Commission in 1987. Since that time, this subject has been the most cited definition in articles, books, and international gatherings. According to the UN Report called "Our common future", sustainable development is development that meets the needs of the present without compromising the ability of future generations to meet their own needs. After presenting this theory, while some scholars have agreed with it, some others rejected the whole idea. The author, while accepting some of the critiques, believes that sustainable development theory is valuable and has important messages for the survival of human being and the whole planet. So, instead of disapproving the theory, tries to overcome the limitations of its conceptualization. The paper suggests that sustainable development in order to be successful, needs a shift in its conceptual framework in an integrated and harmonious manner. In the proposed model, there are three interconnected pillars: subject, space, and time. Subject includes six aspects: political, economic, social and cultural, technological, ecological, and spiritual development. Space refers to local, national, regional, and global arenas. Time describes the situation in the past, present and the scenarios for the future. The article ends with few suggestions which help in facilitating the ground for putting the integrated and harmonious approach into action.
\end{abstract}

Keywords: Sustainable Development, Subject Pillar, Space Pillar, Time Pillar, Sustainability Philosophy, Monitoring Council

DOI: $10.7176 / \mathrm{JESD} / 10-21-05$

Publication date: November $30^{\text {th }} 2019$

\section{Introduction}

The first time that the issue of sustainable development was widely considered by the world was at the World Environment commission hosted by Norway in 1987. At this assembly, Mrs. Graham Harlem Brundtland used the term sustainable development for global development (Henry, 2001). From that time until the next 20 years, the term "sustainable development" has been the most repeated in various books and articles (Crowther, Seifi, \& Moyeen, 2018). At the Rio de Janeiro assembly in 1992, which has been the largest global assembly in the 20th century, the term was reemphasized again (Sedmak, 2014). The main achievement of this assembly was the 21 agenda which indorsed the establishment a sustainable development commission in the United Nations in order to pursue the objectives of the world's countries. Twenty years later, in June 2012, international community representatives gathered again in Brazil to explore the achievements of the Rio assembly. In this assembly it was found that many countries in the world have not fulfilled their commitments. At the climate change meeting, entitled COP21, which was held with the representatives of 195 countries in December 2015 in Paris, there was an emphasis on the cooperation of all the world in dealing with climate change. Also, it was announced that the world countries had no choice but to balance their ambitions (www.cop21paris). The necessity of moving towards renewable fuels, which are specifically clean and free of pollution, was proposed to cope with the global climate change. There was also an emphasis on the need for cooperation of all the world with regard to this issue.

In this meeting, 17 objectives were determined as global development priorities and it was decided that each country according to such objectives, constantly, assess its own progress (Wackernagel, 2017). In recent years, 2015 can be considered as a prominent time to initiate a set of international agreements on the field of sustainable development. The Paris agreement, the Addis Ababa Agenda for Action (AAAA) and 2030 agenda for sustainable development, collectively caused a global passion for an emphasis on future sustainability (Laladhas \& Nilayangode, 2018). The next assembly, in 2016, was held in Morocco which was dedicated to providing a roadmap to achieve the objectives of Paris Agreement (Pagett, 2018). In the business and sustainable development commission, it was estimated that a decade after the realization of the goals of the Paris agreement, approximately 12 trillion dollars and 380 million jobs will be added to the global economy (Polman, 2019). In the recent report of Intergovernmental Panel on Climate Change, it has been warned that without making quick and effective changes with respect to land management, energy, industry, building, transportation, and other matters related to cities the damages that will come out will be unrepairable. The content of the message is quite clear that in order to change the current trend, we need a collaborative and global effort. Most of the existing difficulties and challenges which are associated with sustainability are related to businesses. The only logical way for the future is the change in business practices (Ibid.). Admittedly, the issue of sustainable development has been the basis of many discussions for years, and many experts and pundits have said and written about it. The present article first attempts to describe and critically review the concept of sustainable development and then the author from his 
point of view has a conceptual expansion into the concept of sustainable development theory and proposes an integrated and balanced model for it.

\section{The Definition of Sustainable Development}

According to the Brantland's report entitled: "Our common future," sustainable development is defined as a development which will satisfy the needs of the present time without using future generations' abilities for fulfilling their needs. (Connelly \& Smith, 1999). With this description, sustainable development is a process by which the people of a country satisfy their own needs and improve their lives' level without utilizing the resources that belong to the future generations and wasting future wealth to provide their immediate demands.

Sustainable development is based on the sustainability philosophy. Sustainability refers to the ability of the system to function in the unlimited future. It is a situation in which the desirability does not diminish over time, and the resources that human systems, other biological species, and ecosystems require in performing their activities well do not weaken. Sustainable development is also a set of actions which are driven by the sustainability philosophy. In this type of development, strategies, policies, programs and activities are regularly reviewed, monitored, and revised in terms of sustainability principles. These safeguards are done wisely and consciously for the benefit of the community and for the purpose of protecting natural resources. Moreover, on the basis of the obtained findings, decisions are made whose positive consequences will outweigh their negative consequences.

In sustainable development, human's life protecting systems and other organisms and ecosystems are protected and supported. Also a balance is maintained between the developmental requirements and environmental norms.

\section{Critique of Sustainable Development Theory}

Having the theory of sustainable development been put forward by the United Nations at a global level, a considerable number of development experts and pundits accepted it and endeavored to develop and disseminate the theory. At the same time, some criticized the theory and pointed to its shortcomings. The major criticisms raised in this regard, after the elimination of those which have duplicates and overlaps, are briefly presented as follows:

- Weak theoretical foundations and lack of conceptual clarity.

- Emphasis on generational needs rather than human rights.

- Inability to provide a precise definition of the needs of the next generation.

- Lack of logical justification and moral obligation with regard to ignoring the rights of today's generation and emphasizing on the needs of the next generation.

- Lack of legal enforcement guarantees.

- Being one-dimensional and disproportionate with the needs of developing countries (Vaezzadeh, 2014).

- To have a judgmental and sloganistic attitude.

With respect to these criticisms, there is a need for presenting some explanations here. None of the human theories and constructs can be regarded as free from deficiency. For this reason, in the history of science there have always been theorists who have presented their conceptions of reality in a particular way, and since then, new theorists have supplemented those previous theories. Therefore, because of human perceptual limitations, it is obvious that their constructed theories cannot cover all the dimensions of reality and the variables involved in it. With every identified knowledge and cognition, new theories will come up. This is the case for sustainable development theory as well. Certainly but gradually, more and more aspects of this theory will be identified and raised and in terms of conceptual meaningful it will become more tangible and clear.

It is believed that the criticism of any theory should help in improving its content rather than being a means in damaging and destroying it (Paya, 2015). The same rule applies to sustainable development theory too.

Respecting the views of the critics, the author believes that the theory of sustainable development is a valuable and worthwhile theory which is of particular importance to the survival of humans and the entire planet. Hence, it is valuable that, on the one hand, its requirements and norms being incorporated into the strategic policies of all countries and into the operational strategies of all organizations on the other hand. This is done by enacting the necessary laws, regulations, and effective plans to ensure the implementation of those policies and strategies. If these actions are concomitant with training and awareness raising, they can reduce the gap between theory and practice, move away from being sloganistic, change into a public belief, and turn the destructive behaviors into productive behaviors. Likewise, the efficiency of resources and the efficiency of processes can be enhanced through the development of science and technology so that both the present and future generations benefit from the blessings of the world.

Integrated and Balanced Sustainable Development Pattern

In recent years, numerous books and articles have been frequently penned on sustainable development and various models have been proposed accordingly. In the present article, the author, from his point of view, deals with the 
conceptual development of sustainable development and proposes an integrated and balanced model. She tries to avoid uni-dimensionality in sustainable development in which the emphasis is mainly on ecology and the environment. In the proposed model, other dimensions of development in human societies are taken into account as well. Therefore, the integrated and balanced model of sustainable development is presented in three subject, space and time pillars with a holistic perspective.

\section{Subject Pillar}

\section{Political Dimension}

Political development is a process through which the ground for the participation of all individuals, groups, and organizations of society in the political sphere of the country is provided. This dimension is associated with the formulation of developmental policies from different points of views.

A country is regarded as politically developed if it is capable of resolving conflicts of interest related to individual and collective interests, appreciates freedom of opinion and speech, tolerates diversity and pluralism in the media, gives the right to protest and disagree not only to majorities, but also the minorities, and finally considers transparency, accountability, and procedural justice as the basic tenets of the government. In such a system, any advantage or benefit given to an individual or a group is along with full explanations for the public about the 'whyness' and 'howness' of giving that advantage. In this case, there is no place for the domination of particular group, ethnic, religious, and gender benefits or advantages and the ultimate goal of all community activists and stakeholders is the fulfillment of national interests.

\section{Economic Dimension}

In economic development, attention is given to the productive capacities of the society including both human and physical capacities. It also tries to bring about optimal and efficient use of resources and an equitable distribution of benefits. In economic development, the expansion of infrastructures is a community priority especially those infrastructures which are built on a long-term use and sustainable approach.

In an economically developed society, by relying on economic security and confidence in the future, all people enjoy relative prosperity and have sufficient income for their living, education, health, and leisure. Furthermore, reliable sources are considered as future reserves for unpredicted events.

A country can be called an economically developed country only if all people have access to the existing facilities which is achievable just through employment policies, poverty alleviation, the establishment of distributive justice, and so on. Also, the class gap must be adjusted in a way that the situation in which the rich constantly becomes richer and the poor becomes poorer disappear and the intergenerational justice requires to be fulfilled as well.

\section{Social and Cultural Dimension}

In this dimension, the relationship between people is taken into consideration. Social development is achieved when the proper context is provided for the establishment of educational, cultural, health, housing, social security, personal and judicial security systems together with interactive justice. In a socially developed system, the right of citizenship is recognized, civic associations have an active and effective role, and as a consultative arm they adjust the working load of the governments and monitor and control their performance. Through observing the system of government, these organizations make public control practical and real and play an undeniable role in moderating power in society.

\section{Scientific and Technological Dimension}

This dimension of development refers to a situation in which the advancement of science and technology has had an uptrend in terms of both hardware and software. In this case, if the knowledge of applying and localizing new technologies is not verified, there will be no mass of large and small hardware stored in the country. The needs of the society are met through recognition, absorption, mastery of advanced technology and localization.

In this dimension, factors such as the degree of technological advancement, the level of automation, the characteristics and composition of the workforce, the degree of technical complexity and the digital divide in terms of geography (between cities and villages), class, age, and gender are taken into consideration. In a developed society from a scientific and technological perspective, the gap between theory and practice decreases. Knowledge that is not converted into practice will be of little use.

\section{Environmental and Biological Dimensions}

This dimension deals with the relationship between human and nature and is associated with the protection and enhancement of various physical and biological resources and ecosystems. Nature has its own complexities and regulations, and human beings are required to comply with the laws and requirements embodied in it to benefit from its resources. Human's unwise use of natural resources, which continues to increase at a rapid rate, has led 
to a decline in the quality of the environment. Many species have been extinct and this trend is still continued. It is predicted that the world population goes beyond 9 billion by 2050 (Pagett, 2018). The growth of population is now well beyond the threshold level of tolerance and resilience. According to the latest estimates which have been determined so conservatively, human needs are 68 percent higher than the current capacity of the planet (Global Footprint Network, 2017). New research findings suggest that human groups make up only one-hundredth of the world's living things. But this number of humans have destroyed other species hundreds of times faster than natural processes (Darwish, 1998). The existing problems have arisen because of population growth by which the consumption speed has exceeded that of reproduction of resources in the planet and humans have made no effort to protect other biological species. One of the underlying laws of nature is the existence of ecological niche. Different organisms and biological species are largely influenced by their environmental requirements and are enclosed in their ecological niche. Ecological niche refer to all physical, chemical, and environmental characteristics that determine the status of an organism. If these characteristics change, the organism which is affected by them will face problems that may lead to its destruction. Humans have a distinctive feature among other beings in the universe and that feature is the possibility of ecological release from ecological niche. This advantage together with self-made technology led human to get out of his biological space and conceive himself as the lord of environment and nature. In this situation, human regarded everything that was in nature as its own and as a tool for its use. What has been neglected among these was the very nature itself as an independent and valuable being. In fact, human has forgotten that he, too, is simply a part of the numerous components of the universe and is required to establish a reasonable and balanced relationship with other parts of such universe. Hence, the unwise exploitation of the nature has disrupted the planned system of the nature in a way that we are seeing the effects of nature's rebellion and protest all over the world today. The author believes that the advantage of using intelligence and technology, enjoying ecological release and freedom to do things in many ways, should be accompanied with ecological responsibility. Human kind is responsible to protect the ecological niche for other species all over the globe (Zahedi, 2010).

It is now the time for human to rectify the wrong path he has taken in recent centuries because of the potential and transcendent intelligence and wisdom entrusted to him. In fact, ecological liberation and the advantage of having science and technology have placed great responsibility on human's shoulders which is protecting the ecological nests of other biological species. The acceptance of this responsibility and believing in it necessitates changes to happen in the lifestyle of the people (Zahedi, 2010). In the dimension of environmental development, reasonable and prudent use of natural resources for the present generation and the endurance of this utilization for the future generations is taken into consideration. In this dimension, intergenerational justice is considered.

\section{Spiritual and Social Vitality Dimension}

This dimension refers to a situation in which factors related to spiritual beliefs, psychological security, happiness, and satisfaction and social vitality are given the opportunity to emerge. Such factors encourage work, activity, creativity, and the multifaceted promotion of life quality. Happiness, optimism, hope and positive thinking, belief in the existence of a direct relationship between individual and collective effort and the enjoyment of privileges and benefits in different areas, without any discrimination, are all institutionalized in a society wherein the dominant values of man and women and young and old are taken into account. In a spiritually and socially developed society, the level of self-confidence in individuals increases and their ability to tolerate life's ups and downs for returning to normal status arises as well. The problems of life and work, the difficulties, and conflicts and failures that arise, are lessons to be learned and are considered as opportunities for putting learning, experiences, and skills into practice.

Happiness and vitality lead to better interpersonal relationships, more efficient social interactions, less stress, and a stronger body immune system. These factors all contribute to the physical and mental health of individuals in the society. People who enjoy these blessings have a strong motivation to strive owing to their realistic optimism and hope for the future. They also lead themselves and their communities to a high quality and transcendent life.

\section{Space Pillar}

The policies of an integrated and balanced sustainable development need to be implemented at four levels as follows:

- Local level

- National level

- Regional level

- Global level

\section{Local Level}

An integrated and balanced sustainable development can only be achieved when the requirements and norms of sustainability are met all over the planet. By looking at the results of human activities done in the past, we realize 
that in most societies the process of development has been very uneven and unbalanced at all the four levels.

The modification of the development process requires sustainable instructions to begin simultaneously at all the four levels. Obviously the most basic level is that of local domain. At this level, the requirements of sustainable development have been combined with local values and indigenous culture and they have become practical indices in this regard.

By decentralizing and distributing central power to local networks, it is possible to run and implement a desirable ruling system. Institutions, structures, and decision-making processes approach local areas by which an opportunity to hear people's voices is provided. Public participation in managing local affairs has been well recognized and the likelihood of applying effective monitoring of performances increases as well.

\section{National Level}

If local governance is done wisely and prudently, the necessary context for implementing the policies of an integrated and balanced sustainable development at the national level is provided as well. Policies formulated at the national level should be coherent enough and reflect a sense of belonging and reciprocal relationship between local and national domains.

National development policies should be regulated according to land-use planning so that economic and social activities are best distributed among different regions of the country. In this regard, attention is given to human resources and population distribution, on the one hand and to other natural resources and climate status on the other hand. Hence, the best way to distribute economic and social activities across the territorial area is chosen and implemented monolithically within the framework of sustainable development requirements.

\section{Regional Level}

From the perspective of an integrated and balanced sustainable development, borders and national spaces cannot be very crucial. The national and local domains that are enclosed within national boundaries are not only influenced by the policies and practices of their respective governments but also by the positive and negative consequences of the activities and practices of other countries in the region. In fact, it can be said that the range of policies and decisions made in neighboring countries is significantly expanded to the inland areas and can affect the internal status of the countries.

For example, references can be made to policies in Kazakhstan and Uzbekistan regarding Aral Lake, drying up of the Hoor-al-Aim Wetland in Iraq, restrictions imposed by the Afghan government on the Hirmand River, and so on. All of these actions have had a devastating effect on our country's internal status from an environmental standpoint and have undermined sustainability norms. Therefore, formulating and implementing coherent and coordinated policies at the regional level is one of the needs of an integrated and balanced sustainable development.

\section{Global Level}

Today, we are living in a world that, in spite of its being very large and diverse, is very small and integrated if we look at it from another angle. Our universe is a unitary entity in which any change or manipulation of its constituents affects the other constituting components. The process of globalization has made this impact even more serious. In fact, the real meaning of globalization is the increasing interdependence of countries on each other.

Globalization is a collection of multidimensional and complex processes that encompass many areas including economics, ideology, politics, culture and the environment. The logic of globalization is primarily rooted in the logic of capitalism, namely the maintenance and expansion of the process of capital accumulation, and thus the economy is at the forefront of the process of globalization (Gills, 2002).

In this realm, globalization is the rapid integration of the global economy, a growing integration which is concomitant with the flow of goods, services, capital, technology and information across national boundaries. The rapid and easy transfer of capital, the constant flow of information, and the mobility of people around the world make crises to get transferred from one country to another. Performing different manufacturing activities in geographically dispersed locations also increases the dependency of countries.

By expanding the range of vision, we can observe the process of globalization in all areas of human life. Besides economic domains, the communications and interactions of countries have extended to other areas including political, cultural, social, scientific, sports, religious, and environmental activities (Zahedi, 2011). Globalization is a continuous process of the historical path of internationalization which has made world's countries interdependent in terms of different dimensions especially environmental.

According to Manuela Lucas, globalization has made your problem our problem. War in one country causes the influx of refugees to other countries, and environmental issues of a country cause disaster in other countries (Lucas, 2004). The best example with respect to the last issue is the recent crisis of dust in the south of our country (Iran). Although internal factors and mismanagement have been effective in its formation, the impact of inappropriate policies in neighboring countries cannot be ignored. 
In short, it can be stated that although world's countries are interdependent in many respects, their dependence and reciprocal impact is ecologically more severe. The events that take place in the northern countries affect the destiny of the southern countries and the events in the eastern countries affect the future of the western countries. According to Anthony Giddens, social events in distant lands are tied to the local fabric of other societies (Giddens, 1990). The famous saying, "We are all sitting in the same boat" clearly indicates the existence of reciprocal communication between people from different communities.

Integrated and balanced sustainable development is strongly linked to a sustainable global economic system. A key factor in this phrase is the creation of a market wherein the possibility of competition can be afforded by considering economic constraints, a market that generates goods and services while guaranteeing social and environmental sustainability (Estelle, Herlyn, \& Radermacher, 2014). Thus, in order to achieve the goals of sustainable development, besides the environmental realm, it is necessary to make reformations in economic and business realms too.

New economic systems, including the sharing economy, can influence this process. This type of economy increases the likelihood of reducing consumption and improving productivity by purchasing less and sharing more. The mentioned system has the capacity to promote collective consumption behavior. However, this requires the use of more appropriate patterns of governance (Mi \& Coffman, 2019). The use of this emerging economic model which refers to the common utilization of goods and services is now expanding.

Given these facts, it is not enough to implement sustainable development policies in one place or in one country. The regional and global consequences and impacts of human actions are inevitable fates determined for the entire planet which can be in the direction of sustainability and survival or destruction and annihilation. The current process of globalization moves in contrast to the underlying principle and philosophy of sustainable development. Such a process cannot have continuity because it lacks a human appearance on the one hand and is destructive to the environment and contrary to sustainability norms. If this process continues in this way, it will inevitably become a crisis and will destroy the world. Therefore, it needs to be tethered, controlled, and managed. The countries and large companies that are currently improving in the global arena and are enjoying the benefits of the globalization process must realize that these benefits are temporary. The endurance of benefiting from globalization is only possible when it is together with promoted international cooperation.

The international community must actively monitor and manage the globalization process which can be done through informed and active participation. That community should manage the orientations of globalization and by providing financial and credit assistance to countries with less facilities, establishes a system from which the entire human society derives its benefits.

At international gatherings, developed countries often promise to provide financial aid to developing countries, but legally these promises do not make obligations for them and are inadequate to support underdeveloped countries (Pagett, 2018). The need for rethinking and revisiting the global policies is strongly felt now, otherwise inequality and deprivation will spread throughout the world and its negative and unintended consequences will hurt all people with no exemption. One of the experts has reflected this requirement ranging from ego centric (me), to ethno centric (us), and finally to world centric (all of us) (Wilber, 2001).

The management over the globalization process must be done in accordance with the requirements of integrated and balanced sustainable development so that all countries in the world can benefit from its achievements and results.

The most rational way in this regard is to choose a perfect alternative to the unrestrained globalization and that is a balanced sustainable development at the global level. We all must believe that besides our individual responsibilities, have to fulfill a set of global tasks as well. To fulfill these responsibilities, we must begin the space pillar of sustainable development from our ecosystems and environments and expand it to the whole world and the entire planet.

\section{Time Pillar}

As noted in the previous pages, sustainable development refers to a development that does not jeopardize the future. In other words, besides the development and excellence of the present generation's life, focuses on supporting future generations too. Therefore, the time pillar of sustainable development can be divided into three areas as following:

- Past Performance

- Current Situation

- $\quad$ Predicting the Future (Figure 1) 


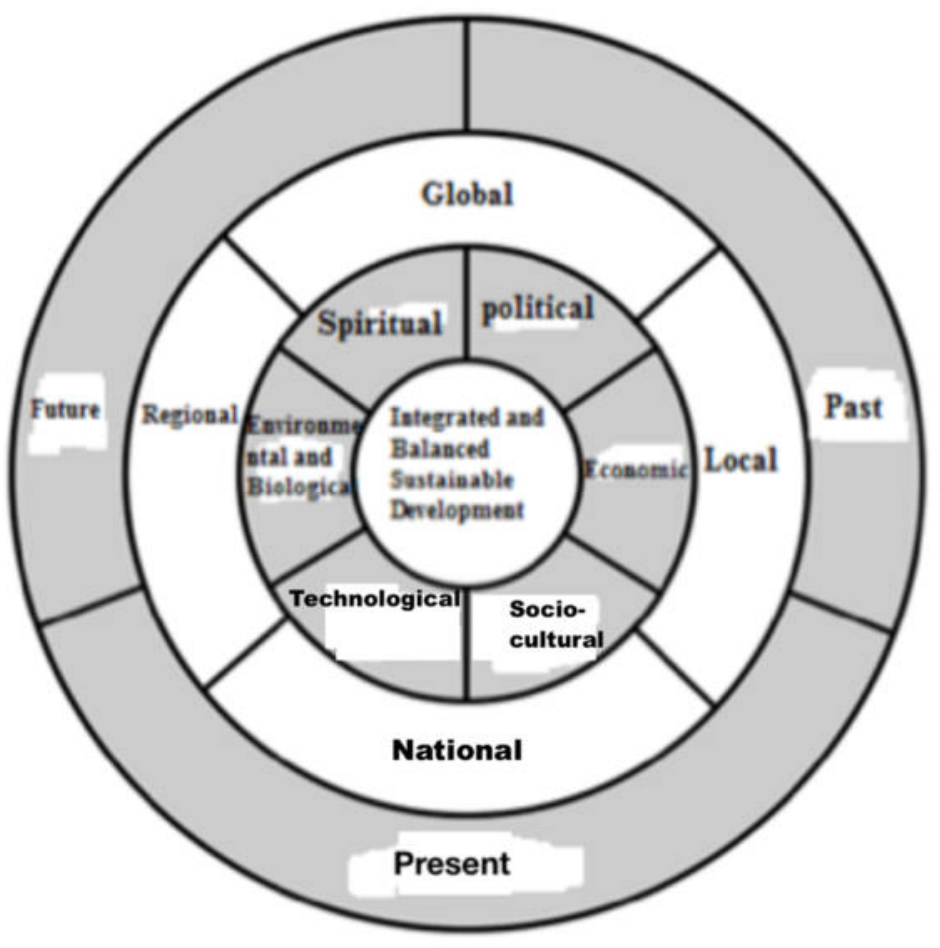

Figure 5. Integrated and Balanced Sustainable Development Model

\section{Past Performance}

In any kind of policy and planning, it is necessary to get to know about the past events and processes. The more complete and accurate this information is, the deeper the knowledge of past events becomes. Through an unbiased review and scientific analysis of past information, we can obtain a reality-based picture of past experiences and use it in determining the future direction.

To examine the performance in the past centuries, we can simply consider the relationship between humans and the nature. We have so far looted and destroyed the resources of the nature. Rather than identifying ourselves as a member among other numerous members of the universe, we have considered everything as ours and perceived ourselves as the possessor of the power of the world. We have regarded uncalculated use as our right and have made use of natural resources far beyond our actual share unaware of the fact that nature is also fed up and reacts to our destructive and devastating actions. The result of such behaviors has been a waste of natural resources and a deterioration of the potential and actual capacity of nature for current and future generations.

\section{Current Situation}

In the present situation, the destructive trend of human activities continues as well. While world conferences have repeatedly emphasized the devastating effects of polluting and destructive actions of human beings, such activities have not yet been controlled and are continuing. Although some efforts have been made in some countries, but unfortunately the anthropocentrism attitude is still dominating the ecocentrism and economic justifications as well as personal interests are yet prevailing rational logics and collective interest.

The reality is that due to improper human life style in the past and its continuation to the present, a great load of problems has been made in the world which in turn have put life on the planet in a danger.

In the UN Millennium Development Report, which is produced with the participation of the representatives of governments, NGOs, academics and local communities, the participants have examined the consequences of ecosystem change on human welfare. According to this report, all human beings are dependent on ecosystems for having a good, healthy, and safe life. For centuries nature has satisfied human needs for food, water, air, and energy. But, currently owing to the over-exploitation in extracting natural resources the capacity and ability of the planet to meet human needs has been severely weakened. The findings of this investigation present an unpleasant picture of the current status in which there are reduced ecosystem services, increased climate change, increased crises and natural disasters, increasing problems caused by various contaminants, and intensification of mass extinction of species in a way that some species are vanishing with a pace thousands times 
faster than normal. It is obvious that such a quick process will eventually lead to the disappearance of humans themselves (United Nations Office, New York).

Considering the environmental problems of the continent as perilous, the Asia Development Bank has pinpointed that the lives of Asians are under threat. According to its report, the current environmental status of Asia and ignoring the pitfalls threaten the economies of the countries of this region. Based on this report, of the 15 most polluted cities in the world, 12 are in Asia. The continent's unique forests are on the verge of extinction and huge damages are done to its rich and diverse marine resources. The mentioned bank has warned Asian governments to be prepared for dealing with this situation as soon as possible.

The situation is very dreadful concerning the oceans as well. While the oceans have the ability to regulate the climate and protect different species, the value of this enormous and vital resource is not properly understood. Today, only about five percent of the world's food consumption is provided by the oceans. If the oceans are to be used in solving the problem of world hunger in the areas of food, medicine, and energy there must be taken logical steps to keep these precious resources clean and healthy. Global warming, ship pollutants, various wastes, illegal and excessive fishing, extinction of marine species, and the massive influx of plastics are all dangers that are currently threaten the oceans. To benefit from this enormous capacity we must take actions quickly (Solberg, 2019).

In our country (Iran), there are many examples of environmental negligence too. For example, we can refer to cases in the north and the south of the country. In the north of the country, wildfires in Golestan's forests frequently occur in the areas of Gorgan, Minoodasht, Aliabad Katul, and adjacent forests which destroy the country's rich and valuable environmental resources. In the south of the country, Asaluyeh and the environmental damages done by the South Pars gas field, which is economically inevitable, is the best example. The existence of multiple gas torches in different phases and petrochemical complexes, leakage of various gases, discharge of industrial wastes, threat of natural vegetation (flora), drying of the sea, etc., have disturbed the order and ecological balance of the area.

\section{Predicting the Future}

According to Iran's Constitutional Law (principle 50), the protection of the environment for the future generations is considered as a public duty and based on the Third and Fourth Development Plans, damage to the environment is regarded as a crime. The fulfilment of these requirements needs a purposeful and deliberate intervention in the development process.

With the continuation of the current trend, no future can be imagined for the world. Hence, from this day on we must be determined to save the planet and by so doing guarantee human and other species' lives. There is no time left to us to waste. We should learn from past mistakes and prevent their reoccurrence.

Now it is the time for reformers and foreseers to step up to compensate the past mistakes and seek the help of experienced pundits and experts. By developing different scenarios and using futurology methods, they need to take actions immediately and stop the destructive activities that have happened in the past and continued to the present. The first step is to raise knowledge and awareness followed by operational measures without wasting the time. This important issue requires the harmony and cooperation of all societies. Everybody must believe that the goal of achieving a unified and balanced sustainable development will only be achieved through everyone's cooperation and involvement.

\section{Conclusion}

Without doubt, an integrated and balanced sustainable development is achievable. It entails some prerequisites the most fundamental of which is a conscious, responsible, and efficient management system. Therefore, it is incumbent upon the leaders, officials, policymakers, and decision makers of country to adopt strategies that integrate the development goals into one another. With a purposeful and deliberate intervention, they should try to guide the country towards a balanced and harmonized development across all the six subject dimensions, the four space levels, and present and future time areas. Any attempt for one-dimensional development regardless of other dimensions will result in nothing but inconsistency and instability.

The capitalist world seeks consumption and encourages it and adds to the passion for consumption by creating false needs. Likewise, the illogical and superfluous consumption of resources has caused the entire planet to get damaged. This is a global problem and requires a global solution. The author believes that in this world, the most important principle in attitudes, in setting priorities, and in behaviors is the iron principle of personal interest. The author has called it the "iron principle" because it rules over all the other cases. Nevertheless, human interests do not necessarily have convergence and homogeneity in terms of type and size and may be determined differently depending on their relations and system of values (material or immaterial, worldly or otherworldly, immediate or future, more or less, etc.). However, personal interest is both the determinant factor and the descriptor of human behavior (Zahedi, 1997). The most obvious example of this principle is the way people exploit the available resources and excess in consumerism. 
In this regard, it is imperative that all countries in the world including both developed and developing, tackle this global problem through a systemic view, find more influential solutions for it, and put such solutions into practice as quickly as possible. In the competition between wanting and having, we all need to keep our desires at a low level so that we can obtain higher life satisfaction besides observing the rights of future generations. What we are doing today is the basis for our tomorrow. It is wise that this time, we look at personal interests from a wider angle and refine its subject, space, and time pillars. Humanity is a single entity whose survival is contingent upon a fundamental change in the current damaging attitudes. It is now the time for expanding our field of vision and outspread our mental pattern of "I" to "we", "now" to "future", and our "habitat" to "the whole universe".

\section{Suggestions}

The issue of integrated and balanced sustainability development should be pursued in two areas:

1) The public domain

2) The organizational domain

From the public perspective, it is essential that the entire community at all levels be familiar with the requirements of sustainability. The prerequisite for this important issue is the recognition of the realities of today's world from the perspective of sustainable development. The most fundamental and underlying action in this regard is to teach and re-teach these facts at all educational levels. In these instructions, an emphasis must be put on the rights and duties of the individual in the community, environmental rules and regulations, the important responsibility of humans to protect species, the necessity of auditing all activities from an environmental perspective, and the need for active participation and monitoring in the sustainable development process.

Every citizen has a right and is obliged to fulfill some duties owing to its membership in the community. Citizenship rights and obligations operate bilaterally, citizenship rights refer to the obligations of the government towards citizens and citizenship duties are responsibilities and commitments that a citizen is obliged to fulfill in relation to his or her own community. However, with regard to an integrated and balanced sustainable development, the issue of global citizenship and the expected responsibilities is both discussible and teachable. The content of curriculums should be in tune with the audience's level of understanding and start from preschool and continue to doctoral programs. The author's recommendation is to include at least a two-credit course called "the concept of integrated and balanced sustainable development" in all academic disciplines including both humanities and sciences.

From an organizational perspective, the establishment of a sustainable development monitoring council in all organizations and institutions, from school to ministry, will play a key role in recognizing the importance and necessity of implementing sustainable norms. Such a council is obliged to observe and monitor all organizational activities from the perspective of sustainable development. In this council, the representatives of staff, managers, stakeholders, and NGOs (Non-governmental organizations) are present and through real (not superficial) monitoring facilitate the deployment and implementation of solutions identified for reaching a sustainable and balanced development.

In today's complicated world, nobody has the monopoly of reason and wisdom. In other words, none of us is more intelligent than all of us, so we need to think of a way to use everyone's intelligence. By creating a common mental pattern for achieving the goals of integrated and balanced sustainable development, we should ensure that the representatives of all stakeholders are involved in the planning process as well as in the tracking of activities and this is achieved only through effective participation and monitoring. In simple terms, a practical and responsive participation should be along with a comprehensive monitoring and legal enforcement guarantee. If we decide to act upon this notion, we can benefit from this enormous power for the benefit of today's and tomorrow's generations and experience dynamism and perpetuity at the same time.

\section{References}

Connelly, James \& Graham, Smith. (1999). Politics and the Environment, from Theory to Practice. Rutledge, London \& New York.

Crowther, D., Seifi, S., and Moyeen, A. (2018). The goals of sustainable development, responsibility and governance. University of Derby, UK.

Darvishi, Ali (2019), Sixth global demolition of species, Etelaat Newspaper, 93 (27291).

Estelle L. A, Herlyn and Franz Josef Radermacher. (2014). "Sustainability: Challenges for the future" In: Weidinger, C, Fischler, F. and Schmidpeter, R, Sustainable entrepreneurship, Business success through sustainability, Springer, Germany.

Giddens, Anthony. (1990). The Consequences of Modernity. Cambridge, Polity Press.

Gills, Dong Sook. (2002). Economic globalization and women in Asia: Challenges and responses. London, Rutledge, UNESCAP.

Global Footprint Network (2017).

Henry, Jane. (2001). Creativity and perception in management. Walton Hall Publication. 
Laladhas, K. P., Nilayangode, P. \& Oommen V. (2018). Biodiversity for sustainable development. Springer, USA.

Lucas, Manuela. (2004). 'How can we make globalization work for sustainable development', Afrique PALOP: Development et mondialisation seminaire, Universite Libre de Bruxelles, 1-2 Mars.

Mi, Zhifu and Coffman, D'Maris. (2019). The sharing economy promotes sustainable societies. Nature Communications, www.nature.com/articles/s4467-019-09260-4\#fig1.

Pagett, Richard. (2018). Building global resilience in the aftermath of sustainable development, planet, people and politics, Seried editor, Justin Taberham, Palgrave, Macmillan, London, UK.

Paya, Ali, (2015). From critical thinking to critical rationality, model dialogue, Journal of Islamic-Iranian Progress, No. 7. Tehran, Iran.

Polman, Paul. (2019). A business model for sustainability, World Economic Forum, http://weforum.

Sedmak, Clement. (2014). "Sustainability: Ethical perspectives", In: Weidimger, et al, Opcit.

Solberg, Erna. (2019). Why the ocean holds the key to sustainable development? World Economic Forum Annual Meeting, www.weforum.org/agenda/2019/01/the-oceans-hold-the-key-to-sustainable-development.

United Nations. (1987). Report of the World Commission on Environment and Development: Our Common Future.

Vaezzadeh, Sadegh (2014), Critical view of sustainable development theory, $4^{\text {th }}$ Islamic-Iranian Progress Conference, Tehran, Iran.

Wackernagel, Mathis. (2017). Making the sustainable development goals consistent with sustainability. Energy Research, Global Footprint Network, Oakland, Ca., USA.

Wilber, K. (2001). A theory of everything: An integral vision for business, politics, science, and spirituality. Boston, MA: Shambhala Publication.

www.cop21paris.org

Zahedi, Shamsalsadat (2011), Globalization and sustainable development, Journal of Strategic Studies of Globalization, National Center of Globalization, Tehran, Iran.

Zahedi, Shamsalsadat. (2010). Green management an approach toward sustainable tourism. Coastal Tourism Innovators Symposium, Stanford University and Center for Responsible Travel, Stanford, California, USA.

Zahedi, Shamsalsadat (1997), Sustainable development and the iron rule of self-interest, Journal of Public Management, Center for Public Management Training, Tehran, Iran. 